\title{
Adherence to GOLD guideline treatment recommendations among pulmonologists in Turkey
}

This article was published in the following Dove Press journal:

International Journal of COPD

10 December 2015

Number of times this article has been viewed

Elif Sen,' Salih Zeki Guclu, ${ }^{2}$ Isil Kibar, ${ }^{3}$ Ulku Ocal, ${ }^{4}$ Veysel Yilmaz, ${ }^{5}$ Onur Celik, ${ }^{6}$ Filiz Cimen, ${ }^{7}$ Fusun Topcu, ${ }^{8}$ Meltem Orhun, ${ }^{9}$ Hikmet Tereci, ${ }^{10}$ Aylin Konya, " Idilhan Ar," Sevgi Saryal'

'Department of Pulmonary Diseases, Ankara University School of Medicine, Ankara, ${ }^{2}$ Pulmonary Diseases Department, Izmir Dr Suat Seren Surgery Training and Research Hospital, Izmir, ${ }^{3}$ Pulmonary Diseases Department, Istanbul Hospital, Istanbul, ${ }^{4}$ Pulmonary Diseases Department, Adana Prof Dr Nusret Karasu Pulmonary Diseases Hospital, Adana, ${ }^{5}$ Pulmonary Diseases Department, Yedikule Pulmonary Diseases and Surgery Training and Research Hospital, Istanbul, ${ }^{6}$ Pulmonary Diseases Department, Nihat Kitapçı Pulmonary Diseases and Surgery Hospital, Erzurum, ${ }^{7}$ Pulmonary Diseases Department, Atatürk Pulmonary Diseases and Surgery Training and Research Hospital, Ankara, ${ }^{8}$ Department of Pulmonary Diseases, Dicle University School of Medicine, Diyarbakir, ${ }^{9}$ Pulmonary Diseases Department, Uskudar State Hospital, Istanbul, ${ }^{10}$ Pulmonary Diseases Department, Samsun Pulmonary Diseases and Thoracic Surgery Hospital, "'Pulmonary Diseases Department, Novartis Pharmaceuticals, Istanbul, Turkey

Correspondence: Elif Sen Department of Pulmonary Diseases, Ankara University School of Medicine, Mamak Caddesi I2/A, Cebeci, Ankara, 06100 , Turkey

Tel +90 5324527660

Fax +903123106370

Email esen@ankara.edu.tr
Background: Low adherence to Global initiative for chronic Obstructive Lung Disease (GOLD) guideline recommendations has been reported worldwide. There has been no study on the adherence to GOLD guidelines for COPD treatment in Turkey.

Objectives: To investigate the rates of adherence to GOLD 2010 guidelines for COPD treatment among pulmonologists.

Design: A multi-center, cross-sectional, observational study was carried out in eleven pulmonary outpatient clinics across Turkey. Adherence to GOLD was evaluated through hospital records. Demographic and clinical data were recorded.

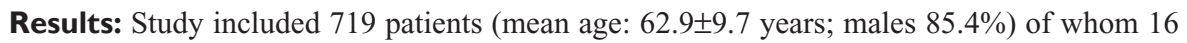
was classified as GOLD Stage I, 238 as II, 346 as III, and 119 as IV, and only 59.5\% received appropriate treatment. Rates of guideline adherence varied across GOLD stages (I, 6.3\%; II, 14.7\%; III, 84.4\%; and IV, 84\%). Causes of inappropriate therapies were overtreatment (Stage I, 100\% and Stage II, 91.1\%), undertreatment (Stage III, 3.3\% and Stage IV, 10.9\%) and lack of treatment (Stage II, 3.8\%; Stage III, 2.3\%; and Stage IV, 5.9\%). The most preferred regimen (43.4\%) was long-acting $\beta 2$-agonist-inhaled corticosteroid-long-acting muscarinic antagonist. Overall, 614 patients $(89 \%)$ received treatment containing inhaled corticosteroid.

Conclusion: Pulmonologists in Turkey have low rates of adherence to GOLD guidelines in COPD treatment. Inappropriateness of therapies was due to overtreatment in early stages and excessive use of inhaled corticosteroid (ICS) in all disease stages.

Keywords: adherence, COPD, Global initiative for chronic Obstructive Lung Disease guidelines, treatment approach, Turkey, overtreatment, inhaled corticosteroid

\section{Introduction}

COPD is characterized by persistent airway obstruction, usually of a progressive nature and associated with an enhanced chronic inflammatory response in airways to noxious particles or gases. ${ }^{1}$ COPD is associated with increased mortality and reduced life expectancy. ${ }^{2}$ Of the 3.8 million mortalities caused by chronic respiratory system diseases in 2010, 2.9 million were by COPD. ${ }^{3}$

The first consensus report for the Diagnosis, Management, and Prevention of COPD was published in 2001 by the Global initiative for chronic Obstructive Lung Disease (GOLD) Committee, and since then it has been updated several times. The major objectives of GOLD are to increase the awareness of COPD and to help the millions of people who suffer from this disease and die prematurely from it or its complications by increasing the standards of care. GOLD guidelines aim for symptom control in the management of COPD ${ }^{1}$. The low adherence to guideline treatment recommendations has been reported in several studies. ${ }^{4-6}$ Under or overprescription cause the 
inappropriate treatment of the disease. ${ }^{4,7}$ Undertreatment of COPD has also been reported in Turkey. ${ }^{8}$ The BOLD study in Adana, Turkey showed that only $12.3 \%$ of the adults with COPD used medication for their diseases in 2004. ${ }^{9}$ The Chronic Diseases and Risk Factors in Turkey Survey reported that $46.1 \%$ of the patients clinically diagnosed with COPD used regular medication in $2011 .^{10}$ To date, there has been no study on adherence to the GOLD guidelines for the treatment of COPD among pulmonary physicians in Turkey. At the time of the study, the patients with COPD were still treated according to the GOLD 2010 guideline recommendations. Therefore, stages and treatments in this study are also classified in accordance with the GOLD $2010 .{ }^{1}$

The aim of this study is to investigate the adherence rates to GOLD 2010 recommendations for stable COPD treatment by pulmonary physicians with a national survey in outpatient clinics of Turkish pulmonary units from different regions of the country.

\section{Methods}

This multi-center, cross-sectional study was conducted with the participation of the pulmonary outpatient clinics of eleven centers (university hospitals, research and training hospitals, state hospitals, and private hospitals) from eight cities (Adana, Ankara, Diyarbakir, Erzurum, Istanbul, Izmir, Kocaeli, and Samsun) across Turkey. These cities were specifically chosen to represent all the geographic regions in Turkey. Sample size estimation has been calculated in order to have the representation of all GOLD stages, and sequential recruitment of 100 patients was anticipated per center.

The study was approved by the Institutional Ethics Committee of Ankara University School of Medicine (November 21, 2010; \#24,596) prior to its initiation and conducted in accordance with the latest version of Declaration of Helsinki and International Conference of Harmonization/ Good Clinical Practice guideline. This study was initiated in December 2010 and closed in November 2011.

The inclusion criteria included doctor's diagnosis of COPD, age $\geq 40$ years, available pulmonary function test (PFT) results from within the past 2 years and COPD treatment data from any time within 6 months of the test, and formal written consent. Patients with a concomitant chronic disease that leads to obstructive (ie, asthma) or restrictive (ie, disseminated bronchiectasis) changes on PFT, with PFT results discordant to GOLD diagnostic criteria (symptoms of COPD, and postbronchodilator spirometric evaluation confirming forced expiratory volume in 1 second $\left(\mathrm{FEV}_{1}\right)$ /forced vital capacity [FVC] $<70 \%$, exclusion of other obstructive lung diseases), ${ }^{1}$ and those with acute COPD exacerbations were excluded from the study analysis. In nonsmoker patients, biomass exposure is considered as one of the major risk factors especially in rural areas, and they were not excluded from the study if they meet the GOLD spirometric diagnostic criteria. Patient recruitment has been performed according to the study inclusion and exclusion criteria in each study center. Patient data were collected from hospital records on standardized forms and following parameters were recorded: any chronic diseases accompanying COPD, age at the time of COPD diagnosis, spirometry results $\left(\mathrm{FEV}_{1}\right.$ and $\mathrm{FEV}_{1} / \mathrm{FVC}$ ) and $\mathrm{COPD}$ treatment recommended within 6 months of this result, and demographic information such as sex, age, location of residence, occupation, level of education, and health insurance status. Overall, 1,125 patients have been recruited, and 719 patients meeting the GOLD diagnostic criteria $\left(\mathrm{FEV}_{1} / \mathrm{FVC}<70 \%\right)$ were included in this analysis.

Appropriateness of treatment was established in accordance with the 2010 GOLD guideline recommendations below:

1. In Stage I, add short-acting bronchodilator when needed.

2. In Stage II, add regular treatment with one or more longacting bronchodilator (long-acting $\beta 2$-agonist [LABA] or long-acting muscarinic antagonist [LAMA]).

3. In Stages III and IV, add regular treatment with one or more long-acting bronchodilator and add inhaled corticosteroid (ICS) for those experiencing frequent exacerbations (GOLD 2010). ${ }^{1}$

All other treatment approaches (under- or overtreatment) were evaluated as inappropriate treatment.

\section{Statistical analysis}

All statistical analyses were performed using SPSS 15.0 software. Data are reported as mean and SD; median, minimum, and maximum; or frequency and percentage. Categorical variables were analyzed using chi-square tests for independent samples. Monte Carlo simulation was used for multigroup comparisons where chi-square test assumptions were not fulfilled. Normally distributed variables were compared using Fisher's exact test. Non-normally distributed variables were compared using Kruskal-Wallis for two groups and Mann-Whitney $U$-test for multiple groups. Bonferroni-corrected Mann-Whitney $U$-test was used for subgroup comparisons within numeric variables. Level of statistical significance was set at $P<0.05$. 


\section{Results}

\section{Patient characteristics}

Seven-hundred and nineteen patients (614 males, 105 females) with mean \pm SD age of $62.9 \pm 9.7$ years were included. Mean \pm SD duration of the disease was $6.0 \pm 5.8$ years. Mean \pm SD values of $\mathrm{FEV}_{1}$ and $\mathrm{FEV}_{1} \%$ were $1.3 \pm 0.6$ and $44.9 \% \pm 15.8 \%$, respectively. Mean $\pm \mathrm{SD} \mathrm{FEV}_{1} / \mathrm{FVC}$ was $56.4 \% \pm 9.4 \%$. Six-hundred and forty-two patients $(89.3 \%)$ had smoking history, and health insurance coverage rate was $95.3 \%$. Of all the patients, $2.2 \%(n=16)$ were in Stage I, $33.1 \%(\mathrm{n}=238)$ in Stage II, 48.1\% $(\mathrm{n}=346)$ in Stage III, and $16.6 \%(\mathrm{n}=119)$ in Stage IV. Mean $\pm \mathrm{SD} \mathrm{FEV}_{1}$ value by stage was $88.6 \% \pm 9.3 \%$ in Stage I, $60.4 \% \pm 8.1 \%$ in Stage II, $39.4 \% \pm 5.6 \%$ in Stage III, and $23.9 \% \pm 4.2 \%$ in Stage IV. Patient characteristics by disease stages were provided in Table 1. There were significant differences between the disease stages in terms of age $(P=0.004)$ and duration of disease $(P<0.001)$. There were also statistically significant differences in sex distribution across stages $(P=0.007)$. Majority of the female patients were in moderate and severe stages. Of the $547(76 \%)$ patients with available data on comorbidities, $412(57.3 \%)$ had at least one comorbidity. The most common comorbidity was hypertension (60.9\%), followed by cardiovascular diseases (43.9\%), diabetes mellitus (22.6\%) and depression/anxiety (10.4\%).

\section{Adherence to GOLD 2010 guideline recommendations for treatment}

Overall adherence to GOLD guideline treatment recommendations for different stages of COPD was $59.5 \%$ in the study group. Appropriate and inappropriate treatment approaches in different stages are represented in Table 2. In Stage I, only one patient (6.25\%) was treated with appropriate regimen, and others were overtreated with regular long-acting bronchodilators or combination of bronchodilators and ICSs. The two most common treatment options were long-acting muscarinic antagonist (LAMA) (37.5\%) and LABA-ICS-LAMA (37.5\%). In Stage II, adherence to GOLD recommendations was $14.7 \%(\mathrm{n}=35)$, and this group was also overtreated by a combination of bronchodilators and ICSs. In this stage, frequently preferred treatment options were LABA-ICS-LAMA (47.5\%), LABA-ICS-LAMAtheophylline (T) (13\%), and LABA-ICS (12.6\%). Of all the patients in Stage II, $81.5 \%(\mathrm{n}=194)$ received treatment containing ICS. In Stage III, adherence to guideline increased to $84.4 \%$ ( $n=292)$ because of the wide use of bronchodilatorICS combinations. The most preferred treatment combination was LABA-ICS-LAMA (45.1\%), followed by LABA-ICSLAMA-T (27.2\%). Of all the patients in Stage III, 89.3\% $(n=309)$ received treatment containing ICS. The undertreatment was due to inappropriate treatment with regular long-/ short-acting bronchodilators without ICS use, 1.7\% $(n=6)$ of the patients were treated by ICS alone without bronchodilator drug and 3.8\% (n=9) were not on any medication for COPD. In Stage IV, the appropriate treatment rate was also high, as $83.2 \%(\mathrm{n}=99)$ received dual, triple, and quadruple therapies with bronchodilators and ICSs. The most preferred regimens were LABA-ICS-LAMA and LABA-ICS-LAMA-T combinations (both $31.1 \%$ ). Of all the patients in Stage IV, $87.3 \%(n=104)$ received treatment containing ICS. The

Table I Patient characteristics by stage of disease

\begin{tabular}{|c|c|c|c|c|c|c|}
\hline & \multirow[t]{2}{*}{ Total } & \multirow{2}{*}{$\frac{\text { Stage I }}{n=16}$} & \multirow{2}{*}{$\frac{\text { Stage II }}{n=238}$} & \multirow{2}{*}{$\frac{\text { Stage III }}{n=346}$} & \multirow{2}{*}{$\frac{\text { Stage IV }}{n=119}$} & \multirow[t]{2}{*}{ P-value } \\
\hline & & & & & & \\
\hline Age (years), mean \pm SD & $62.9 \pm 9.7$ & $59.75 \pm 8.37$ & $62.21 \pm 10.26$ & $64.17 \pm 9.76^{d}$ & $61.24 \pm 7.94^{c}$ & $0.004^{z}$ \\
\hline \multicolumn{7}{|l|}{ Sex, n (\%) } \\
\hline Male & $614(85.4)$ & $16(100.0)$ & I89 (79.4) & $303(87.6)$ & $106(89.1)$ & $0.007^{x}$ \\
\hline Female & $105(14.6)$ & $0(0.0)$ & $49(20.6)$ & $43(12.4)$ & $13(10.9)$ & \\
\hline Duration of disease (years), mean (SD) & $6.0 \pm 5.8$ & $4.19 \pm 82^{d}$ & $4.82 \pm 4.93^{\mathrm{c}, \mathrm{d}}$ & $6.18 \pm 5.34^{b}$ & $8.04 \pm 7.62^{\mathrm{a}, \mathrm{b}}$ & $<0.00 \mathrm{I}^{\mathrm{z}}$ \\
\hline $\mathrm{FEV}_{1}(\mathrm{~L})$, mean $(\mathrm{SD})$ & $1.3 \pm 0.6$ & $2.63 \pm 0.52^{b, c, d}$ & $1.66 \pm 0.46^{\mathrm{a}, \mathrm{c}, \mathrm{d}}$ & $1.16 \pm 0.39^{a, b, d}$ & $0.75 \pm 0.24^{\mathrm{a}, \mathrm{b}, \mathrm{c}}$ & $<0.00 \mathrm{I}^{\mathrm{z}}$ \\
\hline $\mathrm{FEV}_{1}(\%)$, mean $(\mathrm{SD})$ & $44.9 \pm 15.8$ & $88.56 \pm\left. 9.3\right|^{b, c, d}$ & $60.40 \pm 8.05^{\mathrm{a}, \mathrm{c}, \mathrm{d}}$ & $39.39 \pm 5.56^{\mathrm{a}, \mathrm{b}, \mathrm{d}}$ & $23.95 \pm 4.17^{\mathrm{a}, \mathrm{b}, \mathrm{c}}$ & $<0.00 \mathrm{I}^{\mathrm{z}}$ \\
\hline Patients with health insurance, $n(\%)$ & $685(95.3)$ & $16(100.0)$ & $229(97.4)$ & $323(96.1)$ & $117(100.0)$ & $0.149 y$ \\
\hline$>20$ pack-year smoking history, $\mathrm{n}(\%)$ & $525(73)$ & $14(87.5)$ & $169(81.6)$ & $248(81.6)$ & $94(86.2)$ & $0.655^{x}$ \\
\hline Smoking history, $\mathrm{n}(\%)$ & $642(89.3)$ & $16(100.0)$ & $210(88.2)$ & $306(88.4)$ & $110(93.2)$ & $0.222^{x}$ \\
\hline Active smoker & $194(27)$ & $6(37.5)$ & $66(31.4)$ & $94(30.7)$ & $28(25.5)$ & $0.622^{x}$ \\
\hline Former smoker & $448(62.3)$ & $10(62.5)$ & $144(68.6)$ & $212(69.3)$ & $82(74.5)$ & \\
\hline Nonsmoker & $76(10.7)$ & $0(0.0)$ & $28(I I .8)$ & $40(11.6)$ & $8(6.8)$ & \\
\hline
\end{tabular}

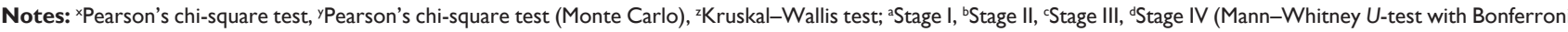
correction, $P<0.008$ ).

Abbreviation: $\mathrm{FEV}_{1}$, forced expiratory volume in I second. 
Table 2 Treatment adherence to GOLD 2010

\begin{tabular}{|c|c|c|c|c|}
\hline GOLD stage & Appropriate treatment & n (\%) & Inappropriate treatment & n (\%) \\
\hline \multirow[t]{6}{*}{ I } & Short-acting & $\mathrm{I}(6.25)$ & LAMA & $6(37.5)$ \\
\hline & bronchodilators when & I (6.25) & LAMA-LABA & $I(6.25)$ \\
\hline & needed & & LABA-ICS & $I(6.25)$ \\
\hline & Total & & LAMA-T & I (6.25) \\
\hline & & & LABA-ICS-LAMA & $6(37.5)$ \\
\hline & & & Total & $15(93.75)$ \\
\hline \multirow[t]{10}{*}{ II } & LAMA & $12(5)$ & ICS & $8(3.4)$ \\
\hline & LABA-LAMA & $20(8.4)$ & LABA-ICS & $30(12.6)$ \\
\hline & LAMA-T & $3(1.3)$ & LAMA-ICS & $4(1.7)$ \\
\hline & Total & $35(14.7)$ & ICS-SABA-SAMA & $\mathrm{I}(0.4)$ \\
\hline & & & LAMA/LAMA-ICS-T & $6(2.5)$ \\
\hline & & & LABA-ICS-LAMA & $113(47.5)$ \\
\hline & & & LABA-ICS-LAMA-T & $31(13)$ \\
\hline & & & ICS-SABA-SAMA-T & $I(0.4)$ \\
\hline & & & No drug use & $9(3.8)$ \\
\hline & & & Total & $203(85.3)$ \\
\hline \multirow[t]{11}{*}{ III } & LABA-ICS & $30(8.6)$ & LABA & $2(0.6)$ \\
\hline & LAMA-ICS & $\mathrm{I}(0.3)$ & LAMA & II (3.2) \\
\hline & LABA/LAMA-ICS-T & II (3.2) & $\mathrm{T}$ & $4(1.2)$ \\
\hline & LABA-ICS-LAMA & $156(45.1)$ & ICS & $6(1.7)$ \\
\hline & LABA-ICS-LAMA-T & $94(27.2)$ & LABA-LAMA & $5(1.4)$ \\
\hline & Total & $292(84.4)$ & LABA-T & $\mathrm{I}(0.3)$ \\
\hline & & & LAMA-T & $5(1.4)$ \\
\hline & & & LABA-LAMA-T & I $(0.3)$ \\
\hline & & & ICS-SABA-SAMA & II (3.2) \\
\hline & & & No drug use & $8(2.3)$ \\
\hline & & & Total & $54(15.6)$ \\
\hline \multirow[t]{8}{*}{ IV } & LABA-ICS & $17(14.3)$ & LABA & I $(0.8)$ \\
\hline & LAMA-ICS & I $(0.8)$ & LAMA & $\mathrm{I}(0.8)$ \\
\hline & LABA/LAMA-ICS-T & $7(5.9)$ & ICS & $5(4.3)$ \\
\hline & LABA-ICS-LAMA & $37(31.1)$ & LABA-LAMA & $4(3.4)$ \\
\hline & LABA-ICS-LAMA-T & $37(31.1)$ & LABA-T & $\mathrm{I}(0.8)$ \\
\hline & Total & $99(83.2)$ & LABA-LAMA-T & $\mathrm{I}(0.8)$ \\
\hline & & & No drug use & $7(5.9)$ \\
\hline & & & Total & $20(16.8)$ \\
\hline Total & & $427(59.4)$ & & $292(40.6)$ \\
\hline
\end{tabular}

Abbreviations: ICS, inhaled corticosteroid; LABA, long-acting $\beta 2$-agonist; LAMA, long-acting muscarinic antagonist; SABA, short-acting $\beta 2$-agonist; SAMA, short-acting muscarinic antagonist; $\mathrm{T}$, theophylline.

inappropriate treatment approaches were one or more longacting bronchodilator administrations without ICS, use of ICS only $(4.3 \%, \mathrm{n}=5)$, and lack of treatment $(5.9 \%, \mathrm{n}=7)$.

According to these findings, while $59.5 \%$ of all patients has been receiving appropriate treatment according to GOLD 2010 guideline, $40.5 \%$ was inappropriately treated. Inappropriate treatment rate were $93.8 \%$ in Stage I, $85.3 \%$ in Stage II, $15.6 \%$ in Stage III, and $16.8 \%$ in Stage IV (Table 2).

The cause of inappropriate therapies was due to overtreatment (100\%) among Stage I. In Stage II overtreatment (91.1\%) was the main reason for guideline discordant therapies, followed by undertreatment (8.9\%), and lack of treatment (3.8\%). Only $14.7 \%$ of the Stage II patients were treated appropriately. In severe and very severe patients, guideline concordant treatment rate was as high as $84.4 \%$ in Stage III and $83.2 \%$ in Stage IV. In Stage III, $13.3 \%$ of patients were undertreated, and $2.3 \%$ of very severe COPD patients did not receive any regular treatment. While undertreatment rate was $10.9 \%$ among Stage IV patients, $5.9 \%$ of stage IV patients had no treatment for COPD.

\section{Analysis of treatment approaches}

The most administered treatment regimen was LABA-ICSLAMA combination (43.4\%, $\mathrm{n}=312$ ), followed by LABAICS-LAMA-T $(22.5 \%, \mathrm{n}=162)$ and LABA-ICS $(10.9 \%$, $\mathrm{n}=78$ ). In patients treated with regular bronchodilators, the most frequently used drug was LABA $(\mathrm{n}=613)$, followed by LAMA ( $n=575), T(n=197)$, short-acting $\beta 2$-agonist $(n=13)$ and short-acting muscarinic antagonistic drugs $(n=13)$, respectively. 
Table 3 Distribution of patients on bronchodilator alone, treatment containing ICS, and no maintenance drug by COPD stage

\begin{tabular}{llll}
\hline & $\begin{array}{l}\text { No maintenance } \\
\text { drugs, } \mathbf{n}(\%)\end{array}$ & $\begin{array}{l}\text { Bronchodilator alone } \\
\text { (no ICS), } \mathbf{n}(\%)\end{array}$ & $\begin{array}{l}\text { Treatment containing } \\
\text { ICS, } \mathbf{n}(\%)\end{array}$ \\
\hline Stage I & $1(4)$ & $8(10)$ & $7(1.1)$ \\
Stage II & $9(36)$ & $35(43.8)$ & $194(31.6)$ \\
Stage III & $8(32)$ & $29(36.3)$ & $309(50.3)$ \\
Stage IV & $7(28)$ & $8(10)$ & $104(16.9)$ \\
Total & $25(100)$ & $80(100)$ & $614(100)$ \\
\hline
\end{tabular}

Abbreviation: ICS, inhaled corticosteroid.

The distribution of patients on bronchodilator alone, treatment containing ICS, and no maintenance drug by COPD stage is shown in Table 3. Of all the patients, 614 (89\%) received treatment containing ICS or ICS alone. The distribution of patients who received ICS was $43.8 \%$ in Stage I, $81.5 \%$ in Stage II, $89.2 \%$ in Stage III, and $86.5 \%$ in Stage IV. Of the $25(3.5 \%)$ patients who were not on any medication, one patient was in Stage I, nine in Stage II, eight in Stage III, and nine in Stage IV. There were 327 (45.5\%) patients on shortacting bronchodilators used as rescue drugs in addition to maintenance therapy. Of all the patients, $56(7.8 \%)$ were on monotherapy, 125 (17.4\%) on dual, 350 (48.7\%) on triple, and $163(22.6 \%)$ on quadruple therapy. Long-term oxygen use rate was $22.4 \%$ ( $\mathrm{n}=112$ patients) in Stages III and IV patients.

\section{Discussion}

This is the first large-scale real-life study in Turkey that reflects the clinical practice of pulmonary specialists through an observational analysis of their adherence to treatment recommendations of GOLD 2010 guideline. The survey was carried out in eleven pulmonary outpatient clinics spread over the national territory. Our findings show that only $59.5 \%$ of overall patients were treated in accordance with the guideline recommendations. While inappropriate treatment regimens were more frequently prescribed for Stages I (93.8\%) and II $(85.3 \%)$, overtreatment in early stages and high rate of ICS administration (89\%) in all stages of disease resulted in improper therapeutic approach according to GOLD 2010 recommendations. In more severe disease stages, guidelineadherent therapeutic approaches were detected by wide use of ICS addition to one or more long-acting bronchodilators. Most of the provider's guideline adherence studies have reported the current practices of general practitioners. A few recent studies have reported similar rates of adherence to guideline recommendations for COPD patients $(37.9 \%-54.7 \%)$ between pulmonologists in other countries. ${ }^{4,5}$

Stage I patients were overtreated with regular long-acting bronchodilators or combination of bronchodilators and ICSs, while guidelines recommend short-acting bronchodilators as initial therapy. In a study conducted among the pulmonary specialists in Italy, Corrado and Rossi reported that 87.7\% of the Stage I patients received regular treatment containing long-acting bronchodilators, ICS alone, or other treatment combinations of ICS plus long-acting bronchodilators. ${ }^{4}$ In a retrospective database study in the United States, Fitch et al reported that only $1 \%$ of the Stage I patients received ICS added to LABA and LAMA, while $6 \%$ received ICS plus single long-acting bronchodilators, and $76 \%$ did not receive any medication in Stage I. ${ }^{11}$ Shariff et al reported that 7.7\% of the patients in Stage I were overtreated and received inappropriate treatment according to the guidelines, in another study on guideline adherence among practitioners and pulmonary specialists. ${ }^{5}$ In our study, only $14.7 \%$ of the patients in Stage II received appropriate therapy, and this was mainly due to overtreatment which was combined long-acting bronchodilators and ICS in $77.3 \%$ of the patients. Other reasons for nonadherent therapeutic approaches were single use of ICS in 3.4\% of the patients and lack of treatment in 3.8\% of the patients. Other studies found $26 \%-49.2 \%$ adherence to GOLD recommendations in this stage. Overtreatment was $67.3 \%$ in one study, ${ }^{4}$ and lack of COPD treatment has been reported in $54 \%$ of the patients in another report for Stage II. ${ }^{11}$ Severe and very severe COPD patients were treated by the combined use of one or more long-acting bronchodilators and ICS which was compliant to GOLD recommendations. This finding can be explained by the features of this group of patients who are more symptomatic and have more frequent exacerbations. Similar studies on guideline adherence in different countries also reported frequent use of dual and triple therapies in Stages III and IV., 4,11 The ICS was frequently used at all stages (43.8\% in Stage I, 81.5\% in Stage II, 89.3\% in Stage III, and $87.4 \%$ in Stage IV) mostly as a part of combination therapy. This study demonstrates that the pulmonary specialists in Turkey have a high tendency to use ICS for the treatment of patients with COPD. In a study by de MiguelDiez et al in Spain, $34.5 \%$ of the patients were prescribed ICS, alone or in combination, with a rate of inappropriate use of $18.2 \% .{ }^{12}$ Asche et al reported that $33 \%$ of the patients received 
combination treatment containing LABA, LAMA, and/or ICS consistent with the current GOLD guidelines. ${ }^{13}$

Pulmonary specialists in our study mostly preferred to prescribe combination treatments containing ICS. This might be related to a number of factors:

1. Inadequate time with patients, which leads to opting for combination therapies that can provide a broad-spectrum treatment.

2. Concerns about symptom control, exacerbation prevention alongside spirometric staging might influence the treatment choice of the specialist.

3. Reimbursement of all COPD drugs in Turkey, making them easily accessible for patients with health insurance.

4. Preferring to prescribe drug groups that are effective in the treatment of both asthma and COPD, where a differential diagnosis is not available.

5. Increasing number of drugs that are provided in combinations and marketing strategies and publicity efforts that promote their use.

In patients treated with regular bronchodilators (alone or a part of a combination therapy), the most frequently used drug was LABA ( $\mathrm{n}=613)$, followed by LAMA ( $\mathrm{n}=575), \mathrm{T}(\mathrm{n}=197)$. Among these results, $\mathrm{T}$ use was prescribed for $27.4 \%$ of stable COPD patients which was remarkably higher than the finding of Corrado and Rossi that reported $2.2 \%$ of patients were using xanthines. ${ }^{4}$ GOLD remark on $\mathrm{T}$ is that it is effective in COPD but, due to its potential toxicity, inhaled bronchodilators are preferred when available. ${ }^{1}$ In our study, this high rate of $\mathrm{T}$ prescription in addition to other inhaled bronchodilators may be explained by the choice of an oral bronchodilator drug even if it has potential toxicity and drug interactions in older patients.

Another finding of this study was that the use of long-acting bronchodilators such as LABA and LAMA alone remains considerably low, and they have been mostly preferred in Stages I, II, and III. The most commonly used bronchodilator in monotherapy was LAMA (4.2\%), and this might be due to its single-dose use and duration of action of more than 24 hours. ${ }^{14,15}$

This study has several limitations. Individual patient data were retrospectively collected through patient records: number of acute exacerbations in the previous year, complete information on comorbidities, adherence to nonpharmacologic interventions were lacking. GOLD guidelines were updated in 2011 to incorporate clinical presentation, including dyspnea as measured by COPD Assessment Test and the modified British Medical Research Council. The updated version of the guidelines incorporates clinical presentation with spirometry findings (GOLD 2011) ${ }^{16}$ This study was undertaken between December 2010 and November 2011. Study protocol had been designed to evaluate GOLD 2010 guideline adherence. Due to lack of knowledge on dyspnea level (Medical Research Council scale) and exacerbation frequency during the last year, patients recruited to the study could not be reclassified according to 2011 revision.

Even this new GOLD classification (updated in 2011) has been changed by considering sypmtoms and exacerbations in addition to spirometric staging, we have not enough data as to the exact superiorities over the old GOLD classification. A very recent analysis showed that GOLD 2011 shifted the overall COPD severity distribution to more severe categories. There were nearly three times more COPD patients in stage D than in former Stage IV $(P<0.05)$. The predictive capacity for survival up to 10 years was significant for both systems $(P<0.01)$ and GOLD 2007 and 2011 did not differ significantly. In this study, the percent predicted $\mathrm{FEV}_{1}$ thresholds of $85 \%, 55 \%$, and $35 \%$ were found better to stage COPD severity for mortality, which are similar to the ones used previously in the GOLD 2010 classification. Increasing intensity of treatment of patients with COPD according to their GOLD 2011 reclassification is not known to improve health outcomes. ${ }^{17}$ The classification recommended by the GOLD committee since 2011 does not seem to be adopted universally throughout Europe. Even if there is a real improvement over the previous classification due to taking into account clinical criteria, quality of life, and exacerbations, criticisms have arisen concerning the choice of certain pathways and therapeutic recommendations not based on prospective studies with a high level of evidence. ${ }^{18}$ At the national level, we do not have any published data on the adoption of the new GOLD 2011 classification. According to the previously mentioned obstacles of the new classification, and lack of the knowledge about the frequency of new GOLD 2011 classification use, instead of the Gold 2010. we believe this data on the guideline adherence among pulmonologists may still reflect the current attitude toward the routine approach of the diagnosis and therapies of COPD in Turkey, and also is concordant with the real life situation around the world.

Turkish Thoracic Society has published an updated report of COPD prevention, diagnosis and treatment in 2014, ${ }^{19}$ and included in the Global Alliance against Chronic Respiratory Disease (GARD) with the Ministry of Health. ${ }^{20}$ The improvement of adherence to national and international COPD guidelines may be achieved by continuing medical education supported by national thoracic societies. Increased awareness of guidelines may influence the standardized care of COPD 
patients, and will have prognostic influences. Promotion of the compliance to evidence-based medicine by health authorities may have also positive effects on the attitude change in the real-life applications.

This study showed that the pulmonary specialists in Turkey have low rates of adherence to GOLD guidelines for treatment of stable COPD patients. Major improper approaches were overtreatment in early stages and excessive use of inhaler corticosteroids in all stages of disease. New strategies are needed to achieve a standardized approach for the treatment of COPD, and thus to improve adherence to guideline recommendations, with particular focus on treatment indications and overtreatment in Turkey.

\section{Acknowledgments}

This work was supported by a total grant from Novartis Pharmaceuticals, Istanbul, Turkey. The sponsor had a role in study design, data collection, data analysis, data interpretation, and writing of the report. Medical writing assistance (translation into English and reviewing the manuscript according to the journal's instructions) was obtained from Prof Sule Oktay, MD, PhD and Cagla Ayhan, MD from KAPPA Consultancy Training and Research Ltd., Istanbul, Turkey funded by Novartis Pharmaceuticals, Turkey.

\section{Disclosure}

Aylin Konya, and Idilhan Ar are Novartis Pharmaceuticals employees. The other authors declare they have no conflicts of interest.

\section{References}

1. Global Initiative for Chronic Obstructive Lung Disease (GOLD). Global Strategy for the Diagnosis, Management and Prevention of Chronic Obstructive Pulmonary Disease; 2010. Available from: http://www. goldcopd.org. Accessed December 21, 2012.

2. Shavelle RM, Paculdo DR, Kush SJ, Mannino DM, Strauss DJ. Life expectancy and years of life lost in chronic obstructive pulmonary disease: findings from the NHANES III Follow-up Study. Int J Chron Obstruct Pulmon Dis. 2009;4:137-148.

3. Lozano R, Naghavi M, Foreman K, et al. Global and regional mortality from 235 causes of death for 20 age groups in 1990 and 2010: a systematic analysis for the Global Burden of Disease Study 2010. Lancet. 2012;380: 2095-2128.
4. Corrado A, Rossi A. How far is real life from COPD therapy guidelines? an Italian observational study. Respir Med. 2012;106:989-997.

5. Shariff R, Cuevas CR, Wang Y, et al. Guideline adherence in management of stable chronic obstructive pulmonary disease. Respir Med.2013; 107:1046-1052.

6. Herrick H, Pleasants R, Wheaton AG, et al. Chronic obstructive pulmonary disease and associated health-care resource use - North Carolina, 2007 and 2009. MMWR Morb Mortal Wkly Rep. 2012;61:143-146.

7. Roche N, Lepage T, Bourcereau J, Terrioux P. Guidelines versus clinical practice in the treatment of chronic obstructive pulmonary disease. Eur Respir J. 2001;18(6):903-990.

8. Buist AS, McBurnia MA, Vollmer WM, et al; BOLD Collaborative Research Group. International variation in the prevalence of COPD (The BOLD Study): a population-based prevalence study. Lancet. 2007; 370:741-750.

9. Kocabas A, Turkyilmaz S, Unalan T, et al. Under-diagnosis and undertreatment of COPD in Adana, Turkey (BOLD-Turkey Study). Eur Respir J. 2006;28(Supp 50):446s.

10. Unal B, Ergor G, editors. Chronic Diseases and Risk Factors in Turkey Survey. Ankara: Ministry of Health of Turkey, 2013. 322.

11. Fitch K, Iwasaki K, Pyenson B, et al. Variation in adherence with Global Initiative for Chronic Obstructive Lung Disease (GOLD) drug therapy guidelines: a retrospective actuarial claims data analysis. Curr Med Res Opin. 2011;27:1425-1429.

12. de Miguel-Diez J, Carrasco-Garrido P, Rejas-Gutierez J, et al. Inappropriate overuse of inhaled corticosteroid for COPD patients: impact on health cost and health status. Lung. 2011;189:199-206.

13. Asche CV, Leader S, Plauschinat $\mathrm{C}$, et al. Adherence to current guidelines for chronic obstructive pulmonary disease (COPD) among patients treated with combination of long-acting bronchodilators or inhaled corticosteroids. Int J Chron Obstruct Pulmon Dis. 2012;7:201-209.

14. Van Noord JA, Bantje TA, Eland ME, Korducki L, Cornelissen PJ; The Dutch Tiotropium Study Group. A randomized controlled comparison of tiotropium and ipratropium in the treatment of chronic obstructive pulmonary disease. Thorax. 2000;55(4):289-294.

15. Casaburi R, Mahler DA, Jones PW, et al. A long-term evaluation of once daily inhaled tiotropium in chronic obstructive pulmonary disease. Eur Respir J. 2002;19(2):217-224.

16. Global Initiative for Chronic Obstructive Lung Disease (GOLD). Global Strategy for the Diagnosis, Management and Prevention of Chronic Obstructive Pulmonary Disease; 2011. Available from: http://www. goldcopd.org. Accessed December 21, 2012.

17. Soriano JB, Lamprecht B, Ramírez AS, et al. Mortality prediction in chronic obstructive pulmonary disease comparing the GOLD 2007 and 2011 staging systems: a pooled analysis of individual patient data. Lancet Respir Med. 2015;3:443-450.

18. Zysman M, Patout M, Miravitlles M, et al. COPD and perception of the new GOLD document in Europe. Workshop from the Sociéte de pneumologie de langue française (SPLF). Rev Mal Respir. 2014;31: 499-510.

19. Turkish Thoracic Society, COPD Working Group. Report of COPD Prevention, Diagnosis and Treatment 2014. Available from: www. toraks.org.tr. Accessed March 27, 2015

20. Yorgancıoğlu A, Yardım N, Ergün P, et al. Integration of GARD Turkey national program with other non-communicable diseases plans in Turkey. Tuberk Toraks. 2010;58(2):213-228.
International Journal of COPD

\section{Publish your work in this journal}

The International Journal of COPD is an international, peer-reviewed journal of therapeutics and pharmacology focusing on concise rapid reporting of clinical studies and reviews in COPD. Special focus is given to the pathophysiological processes underlying the disease, intervention programs, patient focused education, and self management protocols.

\section{Dovepress}

This journal is indexed on PubMed Central, MedLine and CAS. The manuscript management system is completely online and includes a very quick and fair peer-review system, which is all easy to use. Visit http://www.dovepress.com/testimonials.php to read real quotes from published authors. 